\title{
Vascular endothelial growth receptor 1 acts as a stress-associated protein in the therapeutic response to thalidomide
}

\author{
QIN LIU*, TAO YIN*, GUOPING WANG, FUCHUN GUO, YUHONG OU, YI LI and YONGSHENG WANG \\ Department of Thoracic Oncology, State Key Laboratory of Biotherapy and \\ Cancer Center, Collaborative Innovation Center of Biotherapy, West China Hospital, \\ Sichuan University, Chengdu, Sichuan 610041, P.R. China
}

Received October 31, 2016; Accepted June 22, 2017

DOI: $10.3892 /$ etm.2017.5028

\begin{abstract}
Thalidomide (THD) exhibits antitumor effects in several types of cancer. However, the failure of THD to inhibit tumor growth has also been observed in a number of murine models in vivo. The mechanism involved in the therapeutic failure of THD remains unclear. The present study demonstrated that, accompanied by growth-arresting and apoptosis-inducing effects $(\mathrm{P}<0.05)$, THD upregulated vascular endothelial growth factor receptor 1 (VEGFR1) expression levels in CT26 murine colorectal carcinoma cell lines. This in vitro phenomenon was also observed in various other cell lines, including human umbilical vein endothelial cells, SW480, SW620 and HCT116. Reactive oxygen species (ROS) levels were increased compared with those in the untreated control when cells were exposed to THD $(\mathrm{P}<0.05)$. Furthermore, results suggested that ROS suppression may have provoked the induction of VEGFR1 expression to some extent. In addition, the results revealed that THD failed to inhibit CT26 tumor growth in vivo and the expression of VEGFR1 protein was elevated by THD treatment compared with the control group in the murine colorectal tumor model $(\mathrm{P}<0.05)$. The results of further experiments suggested that VEGFR1 was elevated in response to various stress-associated situations, including chemotherapy, radiotherapy and thermotherapy, which indicate that it may act as a stress-associated protein. The present findings provide a foundation for the
\end{abstract}

Correspondence to: Professor Yongsheng Wang, Department of Thoracic Oncology, State Key Laboratory of Biotherapy and Cancer Center, Collaborative Innovation Center of Biotherapy, West China Hospital, Sichuan University, 17, Section 3, South People's Road, Chengdu, Sichuan 610041, P.R. China

E-mail: wangys@scu.edu.cn

${ }^{*}$ Contributed equally

Key words: thalidomide, vascular endothelial growth factor receptor 1, stress response, reactive oxygen species, CT26, human umbilical vein endothelial cells future study of VEGFR1-targeted therapy to enhance the efficacy of current therapies.

\section{Introduction}

Thalidomide (THD) was introduced in the 1950s in Europe due to its antiemetic and sedative effects (1). It is a synthetic derivative of glutamic acid that contains two imide rings: Glutarimide and phthalimide. Due to its neurotoxicity, THD caused devastating teratogenic effects in the 1960s $(2,3)$ and subsequently, the use of this drug was rapidly forbidden as a result. In the early 1990 s, THD was identified to possess antiangiogenic properties (4). In 1999, it was revealed that THD may be used in the treatment of multiple myeloma (5). Additionally, in 2006, the Food and Drug Administration (USA) approved the use of THD for the treatment of multiple myeloma (4). In the following years, a number of studies demonstrated that THD has important antitumor effects in several types of cancer, including prostate, colorectal, non-small-cell lung and breast cancer and renal cell carcinoma (6-10). The mechanism of action of THD is associated with angiogenesis suppression $(3,11)$, proliferation inhibition and apoptosis induction $(12,13)$. THD is also classified as an immunomodulatory drug that inhibits the production of tumor necrosis factor- $\alpha$ and may also affect the production of interleukin (IL)-1 $\beta$, IL-2, IL-4, IL-5, IL-6, IL-10 and interferon- $\gamma(3,11)$. However, the failure of THD to inhibit tumor growth and angiogenesis has also been observed in a murine model in vivo (14). The mechanism underlying the therapeutic failure of THD is uncertain.

Vascular endothelial growth factor (VEGF)/vascular endothelial growth factor receptor (VEGFR) signaling pathways are the key drivers of angiogenesis, and enhance tumor cell survival and promote tumor aggressiveness (15-17). VEGFR-1, also known as fms-like tyrosine kinase receptor 1, has an important role in neovascularization under pathological conditions (18). However, the expression of VEGFR1 is not limited to endothelial cells (19). VEGFR1 has been reported to be expressed by multiple types of cancer cells, including gastric cancer cells (20), colorectal carcinoma cells (21), breast cancer cells (22) and lymphoma cells (23). VEGFR1-positive hematopoietic progenitors have been suggested to initiate the formation of a pre-metastatic niche (24). Furthermore, VEGFR1 may be presented on a subset of macrophages 
in various types of breast cancers, which are significantly enriched in metastatic sites (25). Additionally, the overexpression of VEGFR1 in peripheral blood has been associated with advanced clinical stages of cancer (26) These findings have contributed to the suggestion that VEGFR1 may be a novel therapeutic target for anti-angiogenesis strategies and cancer therapy $(19,27)$. F56, a VEGFR1-specific peptide, has been shown to displace VEGF from its receptor VEGFR1 and inhibit tumor growth $(27,28)$. However, the role of VEGFR1 in the response of cancer therapy requires further investigation.

In the present study, the effect of THD on CT26 tumor cells and human umbilical vein endothelial cells (HUVECs) in vitro was determined. Specifically, its effect on cell proliferation, apoptosis and VEGFR1 expression was investigated. In addition, the effect of THD on reactive oxygen species (ROS), and the effect of ROS suppression on THD-induced VEGFR1 expression were evaluated. Furthermore, whether VEGFR1 acts as a stress-associated protein in response to chemotherapy, radiotherapy and thermotherapy was examined. The findings of this study may be useful for the future application of VEGFR1-targeted therapy with current therapeutics.

\section{Materials and methods}

Reagents. THD, cisplatin, doxorubicin, paclitaxel and 5-fluorouracil (5-FU) were all purchased from Selleckchem (Houston, TX, USA), $N$-acetyl-L-cysteine (NAC) was obtained from Sigma-Aldrich (Merck KGaA, Darmstadt, Germany).

Cell lines and cell culture. CT26, HUVECs, SW480, SW620 and HCT116 were obtained from the American Type Culture Collection (ATCC; Manassas, VA, USA). CT26 and SW480 cells were grown in $100-\mathrm{cm}^{2}$ cell culture plates and maintained in RPMI-1640 medium (Gibco; Thermo Fisher Scientific, Inc., Waltham, MA, USA) supplemented with $10 \%$ heat-inactivated fetal bovine serum (Gibco; Thermo Fisher Scientific, Inc.), $100 \mathrm{U} / \mathrm{ml}$ penicillin and $100 \mu \mathrm{g} / \mathrm{ml}$ streptomycin at $37^{\circ} \mathrm{C}$ in a humidified atmosphere containing $95 \%$ air and $5 \% \mathrm{CO}_{2}$. SW620 and HCT116 cells were maintained in Dulbecco's modified Eagle's medium (DMEM; Gibco; Thermo Fisher Scientific, Inc.) and HUVECs were maintained in DMEM-F12 (Gibco; Thermo Fisher Scientific, Inc.). DMEM and DMEM-F12 were also supplemented with $10 \%$ heat-inactivated fetal bovine serum (Gibco; Thermo Fisher Scientific, Inc.), $100 \mathrm{U} / \mathrm{ml}$ penicillin and $100 \mu \mathrm{g} / \mathrm{ml}$ streptomycin at $37^{\circ} \mathrm{C}$ in a humidified atmosphere containing $5 \% \mathrm{CO}_{2}$. Cells in the exponential growth phase were used for all experiments.

Cell proliferation assays. CT26 cells and HUVECs were plated into 24 -well plates at a density of $1 \times 10^{5}$ cells/well. THD dissolved in dimethyl sulfoxide was incubated with the cells at different concentrations $(0,12.5,25,50$ and $100 \mu \mathrm{M})$ with three replicates being performed for each concentration. Following 24,48 or $72 \mathrm{~h}$ incubation at $37^{\circ} \mathrm{C}$, the cell proliferation was determined manually by cell number counting.

Annexin V/propidium iodide (PI) assay. CT26 cells and HUVECs were seeded into 6-well plates at a density of $2 \times 10^{5}$ cells/well and exposed to THD at various concentrations $(0,25$ and $100 \mu \mathrm{M})$ at $37^{\circ} \mathrm{C}$. Cells were harvested following 24-h incubation and washed twice with PBS. Subsequently, cells were stained using an Annexin V/PI double staining solution from an Annexin V-FITC apoptosis detection kit (BD Pharmingen; BD Biosciences; San Jose, CA, USA) at room temperature, according to the manufacturer's instructions. Following $15 \mathrm{~min}$ of incubation, the Annexin V/PI stained cells were detected using a FACSCalibur flow cytometer (BD Biosciences) and analyzed using CellQuest software (version 5.1; BD Biosciences).

Cell cycle analysis. CT26 cells and HUVECs were seeded into 6 -well plates at a density of $2 \times 10^{5}$ cells/well and incubated with THD at various concentrations $(0,25,50$ and $100 \mu \mathrm{M})$ for $24 \mathrm{~h}$ at $37^{\circ} \mathrm{C}$. Subsequently, cells were harvested and washed three times with cold PBS. Cells were fixed in $70 \%$ ice-cold ethanol overnight, washed twice with PBS, stained with PI/RNase staining buffer (BD Pharmingen; BD Biosciences) at room temperature for $15 \mathrm{~min}$ and detected using a flow cytometer. Data were analyzed using Modifit software (version 4.1; Verity Software House, Topsham, ME, USA).

Cell treatments and protein extraction. CT26 cells and HUVECs were seeded into 6-well plates at a density of $2 \times 10^{5}$ cells/well. Cells were exposed to THD (0, 25, 50 and $100 \mu \mathrm{M})$, cisplatin $(0,0.5,0.8$ and $1 \mu \mathrm{g} / \mathrm{ml})$, paclitaxel $(0,10$, 20 and $40 \mathrm{ng} / \mathrm{ml}), 5$-FU $(0,1,2$ and $4 \mu \mathrm{M})$ and doxorubicin $(0,5$ and $10 \mu \mathrm{M})$, irradiated with 2 Gy X-rays $(29,30)$ or heated at $47^{\circ} \mathrm{C}$ for $3 \mathrm{~min}$ as previously described (31). To inhibit intracellular reactive oxygen species (ROS), the antioxidant NAC ( 2 and $4 \mathrm{mM}$, respectively) was added to the culture media, then they were exposed to $100 \mu \mathrm{M}$ THD for $24 \mathrm{~h}$ at $37^{\circ} \mathrm{C}$. In addition, SW480, SW620 and HCT116 cells were seeded at a density of $2 \times 10^{5}$ cells/well and were exposed to THD at various concentrations $(0,25,50$ and $100 \mu \mathrm{M})$. Following 24-h incubation at $37^{\circ} \mathrm{C}$, all cells were harvested by centrifugation (475 x g for $3 \mathrm{~min}$ at room temperature), washed twice using cold PBS, and subsequently lysed in radioimmunoprecipitation assay lysis buffer (Beyotime Institute of Biotechnology, Haimen, China) on ice for $15 \mathrm{~min}$ for protein extraction.

Western blot assay. Protein concentrations were determined using a bicinchoninic acid assay. Sample proteins (40 $\mu \mathrm{g} / \mathrm{sample}$ ) were separated on $10 \%$ SDS-PAGE and then transferred onto polyvinylidene difluoride membranes. Membranes were blocked with 5\% non-fat milk in Tris-buffered saline with Tween-20 (TBST) at room temperature for $1 \mathrm{~h}$. Membranes were subsequently incubated at $4^{\circ} \mathrm{C}$ overnight with the primary rabbit monoclonal antibodies against VEGFR-1 (cat. no. ab32125), cyclin dependent kinase (CDK)6 (cat. no. ab131439), cyclin D1 (cat. no. ab134175), C-MYC (cat. no. ab39688), B-cell lymphoma-2 (BCL-2; cat. no. ab59348), BCL-2-associated X protein (BAX; cat. no. ab182733) and caspase-3 (ab32351, all 1:1,000; all from Abcam, Cambridge, MA, USA). GAPDH protein was also determined using a specific antibody (dilution 1:1,000, cat. no. 2118; Cell Signaling Technology, Inc., Danvers, MA, USA) as a loading control. The membranes were washed with TBST three times and incubated with the appropriate horseradish peroxidase-conjugated secondary antibody (cat. no. ab6721, 1:5,000; Abcam) at room temperature for $1 \mathrm{~h}$. The membranes 
were washed with TBST three times and visualized using an enhanced chemiluminescence detection system (Beyotime Institute of Biotechnology).

ROS analysis. CT26 cells and HUVECs were respectively seeded at $2 \times 10^{5}$ cells/well in 6 -well plates and incubated with THD at various concentrations $(0,25,50$ and $100 \mu \mathrm{M})$ for $6 \mathrm{~h}$ at $37^{\circ} \mathrm{C}$. Cells were harvested and washed three times with cold PBS. Subsequently, cells were resuspended in diluted 2',7'-dichlorofluorescein diacetate (DCFH-DA) at a cell concentration of $1 \times 10^{6}$ to $20 \times 10^{6}$ cells $/ \mathrm{ml}$ according to the manufacturer's instructions and incubated at $37^{\circ} \mathrm{C}$ for $20 \mathrm{~min}$. Cells were washed three times with serum-free cell culture medium to sufficiently remove DCFH-DA that had not entered the cells (ROS kit, cat. no. s0033; Beyotime Institute of Biotechnology). Analysis was conducted using a flow cytometer and CellQuest software (version 5.1).

Animal models. The present study was approved by the Animal Experimental Ethics Committee of the State Key Laboratory of Biotherapy, Sichuan University (Sichuan, China). A total of 20 female BALB/c mice (6-8 weeks old, 18-20 g) were obtained from the Vital River Laboratory Animal Technology (Beijing, China), and housed in a specific pathogen-free environment (temperature, $21 \pm 2{ }^{\circ} \mathrm{C}$; humidity, 40-70\%; light cycle, $12 / 12 \mathrm{~h}$; free access to food and water). A total of $5 \times 10^{5}$ CT26 tumor cells were injected into the abdominal cavity of mice. Tumor-bearing mice were divided into two groups $(n=10)$ and treatment began at 3 days post-inoculation. Mice in the THD group were administered $100 \mathrm{mg} / \mathrm{kg}$ THD every day by gavage. Mice in the control group received normal saline. The effect of THD on mice was evaluated at day 7 based on body weight, ascites volume and tumor weight.

Immunohistochemical staining. Fresh tumor nodules were harvested, flash frozen and sliced into 4-8 $\mu \mathrm{m}$ sections. Frozen sections were treated with $3 \%$ hydrogen peroxide in methanol for $20 \mathrm{~min}$ to quench endogenous peroxidase activity. Subsequent to washing in PBS (5 min, 3 times; $\mathrm{pH}$ 7.6), sections were blocked with $10 \%$ normal goat serum (cat. no. s8080; Solarbio Science and Technology Co., Ltd., Beijing, China) for $10 \mathrm{~min}$. Sections were subsequently incubated with rabbit monoclonal antibody against VEGFR1 (ab32152, 1:250 dilution; Abcam) overnight at $4^{\circ} \mathrm{C}$, and then washed in PBS (5 min, 3 times; pH 7.6). The washed sections were incubated with biotinylated goat anti-rabbit $\mathrm{IgG}$ (1:100 dilution, cat. no. ZB-2301; OriGene Technologies, Inc., Beijing, China) for 30 min followed by a streptavidin-peroxidase conjugate for $30 \mathrm{~min}$ at room temperature. A solution of $0.02 \%$ diaminobenzidine hydrochloride containing $0.03 \%$ hydrogen peroxide was used as chromogen to visualize peroxidase activity at room temperature for 5-8 $\mathrm{min}$. The preparations were counterstained with hematoxylin at room temperature for $30 \mathrm{sec}$ to $2 \mathrm{~min}$, dried, mounted and examined using light microscopy.

Statistical analysis. All statistical analyses were performed using GraphPad Prism 6.01 software (GraphPad Software, Inc., La Jolla, CA, USA). Data analysis was performed using the one-way analysis of variance and Dunnett's test for multiple groups. The Student's t-test was used for the analysis of two groups. All data were presented as the mean \pm standard deviation of three independent experiments. $\mathrm{P}<0.05$ was considered to indicate a statistically significant difference.

\section{Results}

In vitro effects of THD on the growth of CT26 tumor cells and HUVECs. The effect of THD on murine CT26 colorectal tumor cells in vitro was evaluated. CT26 tumor cells were treated with various concentrations $(0,12.5,25,50$ and $100 \mu \mathrm{M})$ of THD for 24, 48 and $72 \mathrm{~h}$. The number of surviving tumor cells was determined. Results indicated ( $\mathrm{P}<0.001$; Fig. 1A).

As THD has antiangiogenic properties, and endothelial cells have a key role in angiogenesis $(32,33)$, the effect of THD on HUVECs was evaluated. The results revealed that THD inhibited the proliferation of HUVECs compared with the control group (Fig. 1A).

The effect of THD on the apoptosis of CT26 cells and HUVECs was determined using an Annexin V/PI assay. The apoptosis rate was increased following exposure to THD for $24 \mathrm{~h}$ in a dose-dependent manner (Fig. 1B) and this difference was statistically significant $(\mathrm{P}<0.01$; Fig. $1 \mathrm{C})$. Collectively, these data revealed that THD had a growth-arresting and apoptosis-inducing effect on tumor cells and endothelial cells.

Effect of THD on the cell cycle and apoptosis-associated proteins. The effect of THD on cell cycle and apoptosis-associated molecules was investigated. CT26 tumor cells and HUVECs were exposed to different concentrations of THD for $24 \mathrm{~h}$. Flow cytometry revealed that THD arrested the cell cycle at the G0/G1 phase in CT26 tumor cells, and at the $\mathrm{S}$ phase in HUVECs (Fig. 2A).

The protein expression levels of CDK6, cyclin D1, C-MYC, BCL-2, BAX and cleaved-caspase 3 were examined by western blot analysis. CDK6 is a protein kinase that activates cell proliferation and is associated with restriction in the cell cycle (34). Cyclin D1 protein required for progression through the G1 phase of the cell cycle; it is synthesized rapidly and accumulates in the nucleus during the G1 phase and is degraded as the cell enters the $\mathrm{S}$ phase (35). The protein product of the proto-oncogene C-MYC is a transcription factor that regulates a range of cellular processes that serve a key role in cell proliferation, most notably in the regulation of G1 specific cyclin dependent kinases (36). The results indicated that in CT26 cells the protein expression levels of CDK6 were markedly upregulated, whereas the protein expression levels of cyclin D1 exhibited no notable change following THD treatment compared with the control (Fig. 2B). However, exposure of HUVECs to THD downregulated CDK6 protein expression levels as the concentration increased. Conversely, the protein expression levels of cyclin D1 were only marginally increased as a result of THD exposure compared with the control group (Fig. 2B). Furthermore, the protein expression levels of C-MYC were markedly increased in the two cell lines, particularly in HUVECs, following THD treatment (Fig. 2B). BCL-2 is an anti-apoptotic protein, whereas BAX promotes apoptosis (37). In the present study, the protein expression levels of anti-apoptotic protein BCL-2 were downregulated with increased THD concentration, whereas the protein expression 
A

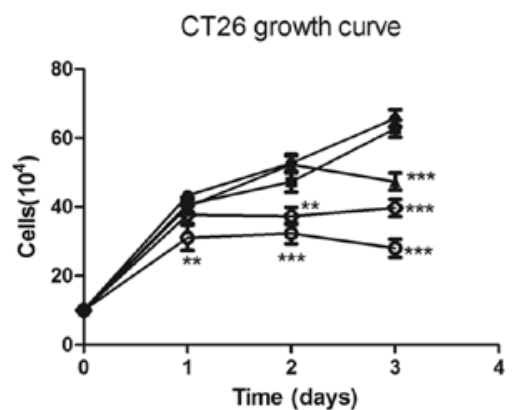

B

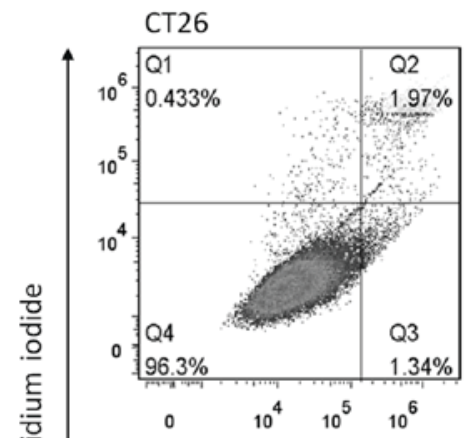

Ст26

HUVEC

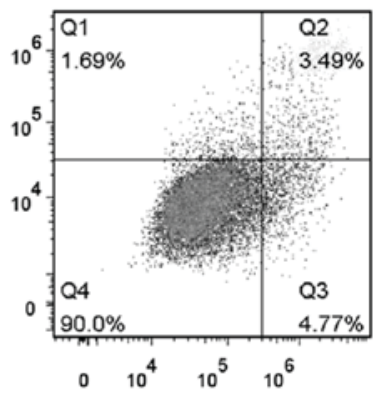

con
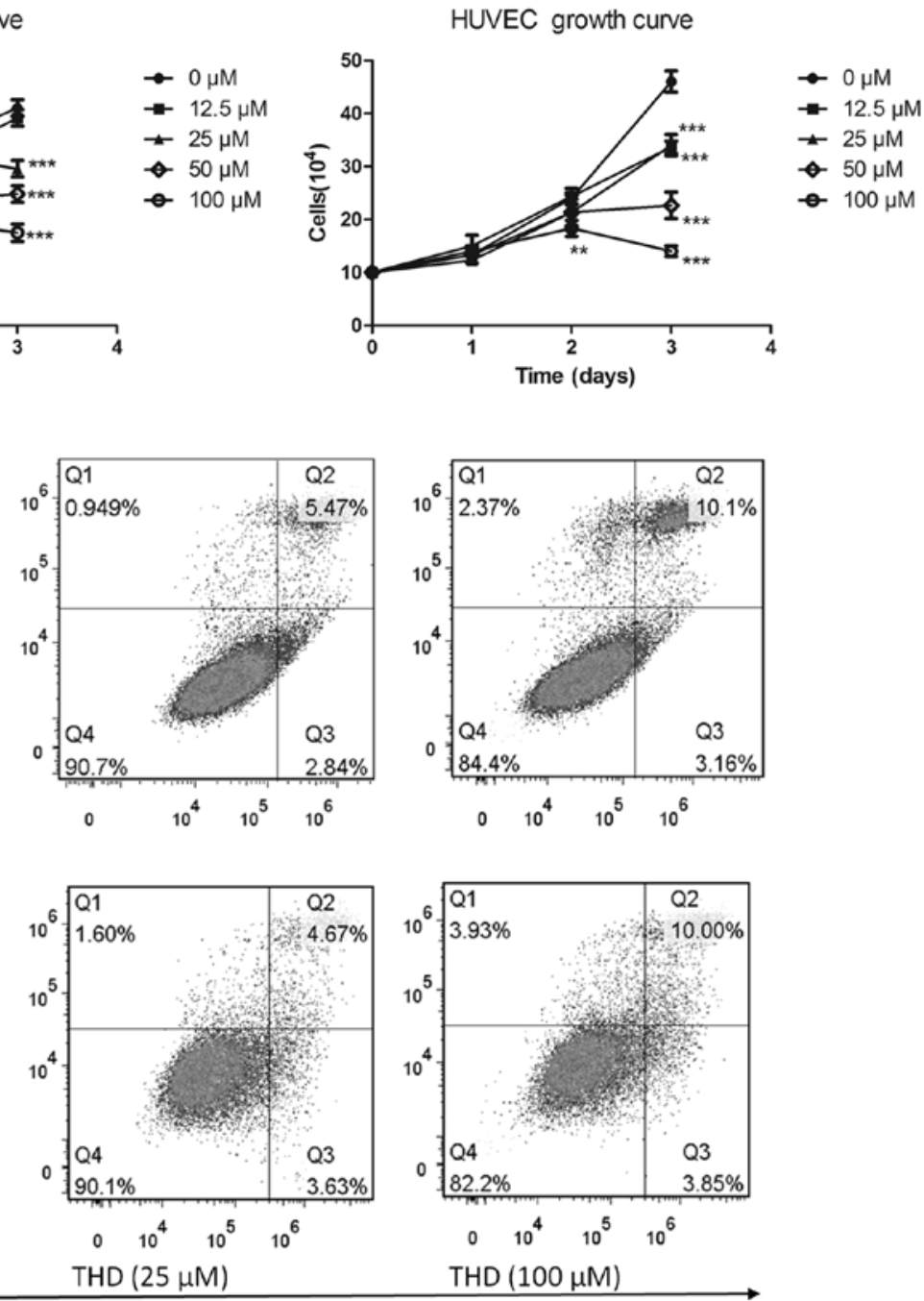

Annexin V-FITC

C

СT26

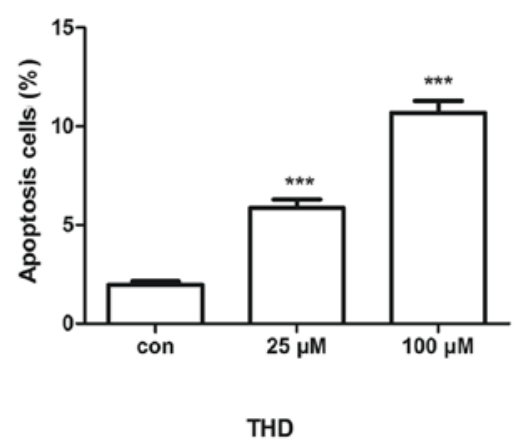

HUVEC

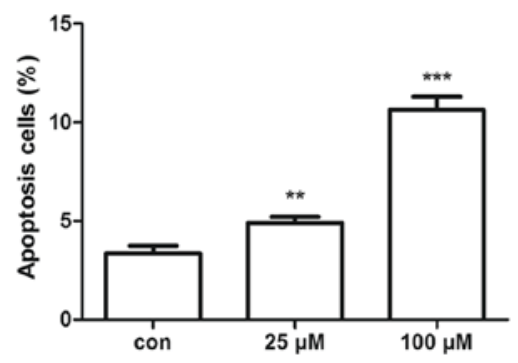

THD

Figure 1. In vitro effects of THD on the growth of CT26 tumor cells and HUVECs. (A) CT26 cells and HUVECs were incubated with increasing concentrations of THD for $0,24,48$ and $72 \mathrm{~h}$, and the number of surviving cells was counted. (B and C) The percentages of apoptotic and necrotic CT26 cells and HUVECs were analyzed using an Annexin V/propidium iodide assay. Data are presented as the mean \pm standard deviation. ${ }^{* *} \mathrm{P}<0.01$ and ${ }^{* * * *} \mathrm{P}<0.001$ vs. Con. THD, thalidomide; HUVECs, human umbilical vein endothelial cells; Con, control.

levels of pro-apoptotic protein BAX and cleaved-caspase-3 were upregulated compared with the control group (Fig. 2C). These findings suggested that THD alters the protein expression levels of cell cycle and apoptosis-associated molecules.

Effect of THD on VEGFR1 expression levels in vitro. To determine whether THD influenced the protein expression levels of
VEGR1 in endothelial cells, HUVECs were exposed to different concentrations $(0,25,50$ and $100 \mu \mathrm{M})$ of THD for $24 \mathrm{~h}$. Results indicated that THD at a high concentration $(100 \mu \mathrm{M})$ markedly upregulated the protein expression levels of VEGFR1 compared with the control group (Fig. 3A). Subsequently, this phenomenon was assessed in tumor cells. The CT26 tumor cells treated with THD exhibited clearly upregulated VEGFR1 

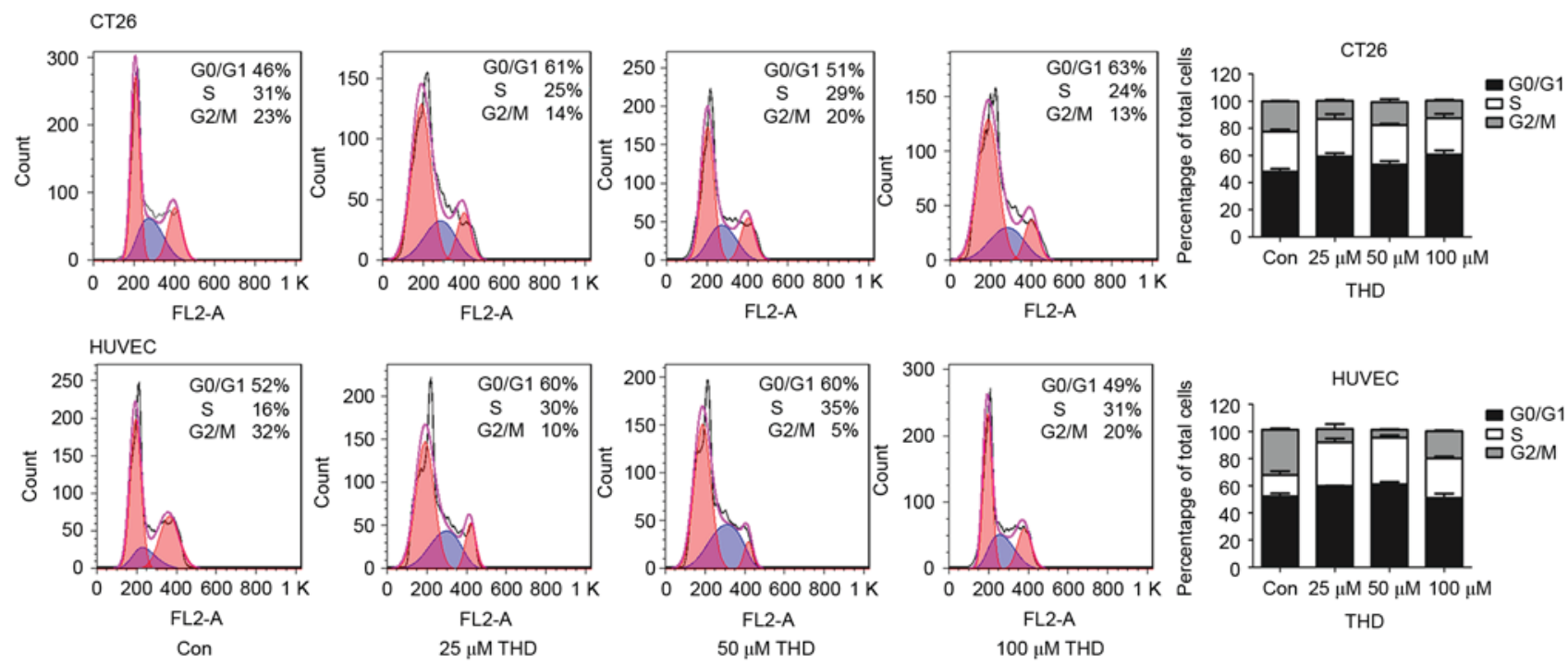

B

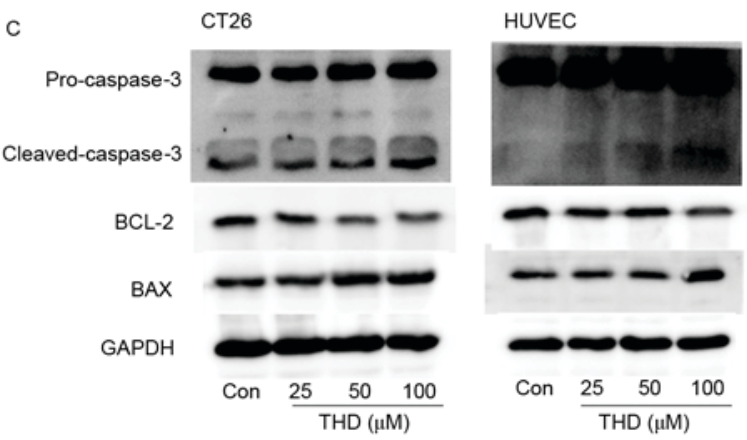

Figure 2. Effect of THD on cell cycle and apoptosis-associated proteins. (A) CT26 tumor cells and HUVECs were incubated with increasing concentrations of THD for $24 \mathrm{~h}$. Cell cycle analysis was performed using flow cytometry. (B and C) Expression of the CDK6, cyclin D1, C-MYC, cleaved-caspase-3, BCL-2 and BAX proteins in the CT26 cells and HUVECs was determined by western blot analysis. Data are presented as the mean \pm standard deviation. THD, thalidomide; Con, control; HUVECs, human umbilical vein endothelial cells; CDK6, cyclin dependent kinase 6; BCL-2, B-cell lymphoma-2; BAX, BCL-2-associated $\mathrm{X}$ protein.

expression levels compared with the control group (Fig. 3B). Furthermore, similar phenomena were observed in the human colorectal cell lines SW480 and HCT116. In the SW620 cell line, no obvious differences in VEGFR1 expression were observed between different dosages of THD. It may be that VEGFR1 expression is only affected by higher concentrations of THD (Fig. 3C). These data suggest that THD upregulates VEGFR1 protein expression levels in vitro.

Effect of THD on ROS and its association with VEGFR1. Considering the cytotoxic effect of THD on CT26 tumor cells and HUVECs, and the upregulation of VEGFR1 observed in vitro, it was speculated that the upregulation of VEGFR1 may be induced by cellular stress caused by THD. The levels of intracellular ROS were subsequently analyzed using the probe DCFH-DA. ROS levels were significantly increased in the two cell types following exposure to THD (Fig. 4A and B). Notably, the ROS antagonist NAC reversed VEGFR1 elevation to some extent in CT26 cells and HUVECs (Fig. 4C). These results suggested that the elevation of VEGFR1 was associated with oxidative cellular stress.

Effect of THD on VEGFRI expression in vivo. To determine the effect of THD upregulation on VEGFR1 protein expression
A

HUVEC

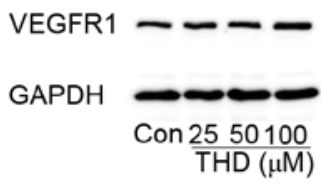

C

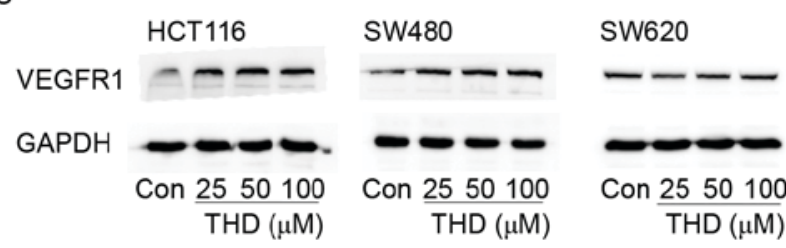

Figure 3. Effect of THD on VEGFR1 protein expression levels in vitro. (A) HUVECs and (B) CT26, (C) HCT116, SW480 and SW620 cells were treated with various concentrations of THD for $24 \mathrm{~h}$. Protein expression levels of VEGFR1 in the various cell types were determined using western blot analysis. THD, thalidomide; Con, control; VEGFR1, vascular endothelial growth factor receptor 1; HUVECs, human umbilical vein endothelial cells.

levels in vivo, CT26 cells were injected into the abdominal cavity of BALB/c mice. The antitumor effect of THD was 

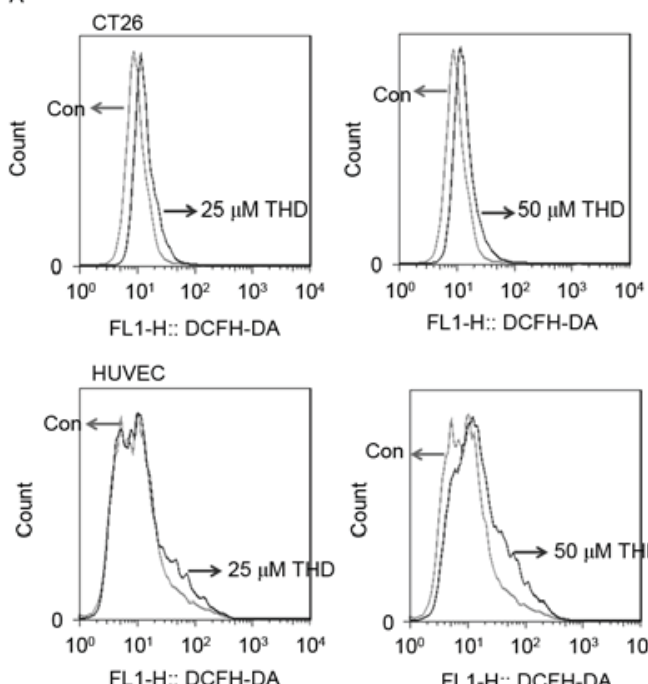
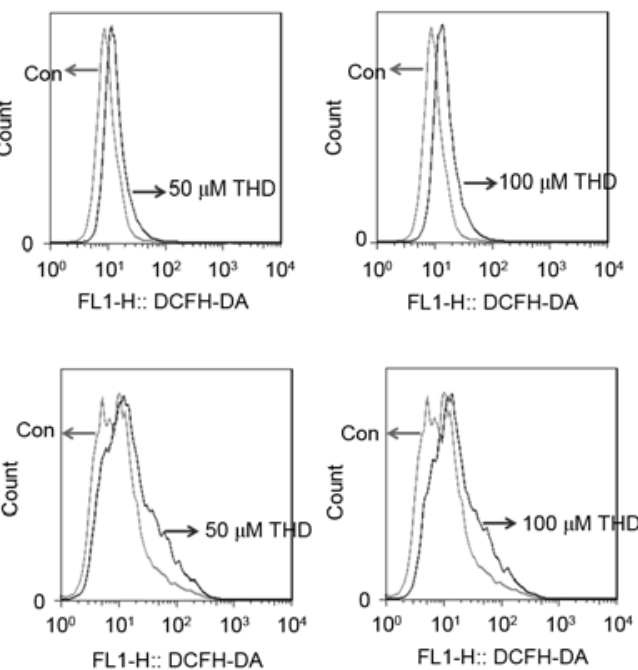

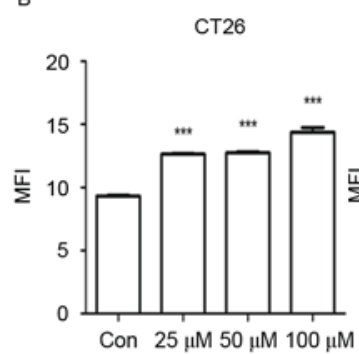

HUVEC

c

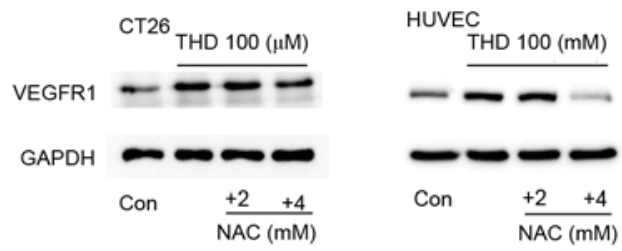

Figure 4. Effect of THD-induced VEGFR1 upregulation on ROS. (A and B) CT26 tumor cells and HUVECs were incubated with indicated concentrations of THD for $6 \mathrm{~h}$. Cells were stained with DCFH-DA and ROS levels were evaluated using flow cytometry. (C) HUVECs and CT26 tumor cells were treated with various concentrations of NAC and then exposed to $100 \mu \mathrm{M}$ THD for $24 \mathrm{~h}$. Expression of VEGFR 1 in the CT2 6 cells and HUVECs was determined by western blotting. Data are presented as the mean \pm standard deviation. ${ }^{*} \mathrm{P}<0.05$ and ${ }^{* * *} \mathrm{P}<0.001$ vs. Con. THD, thalidomide; VEGFR1, vascular endothelial growth factor receptor 1; ROS, reactive oxygen species; Con, control; DCFH-DA, 2',7'-dichlorofluorescein diacetate; MFI, mean fluorescence index; HUVECs, human umbilical vein endothelial cells; NAC, $N$-acetyl-L-cysteine.
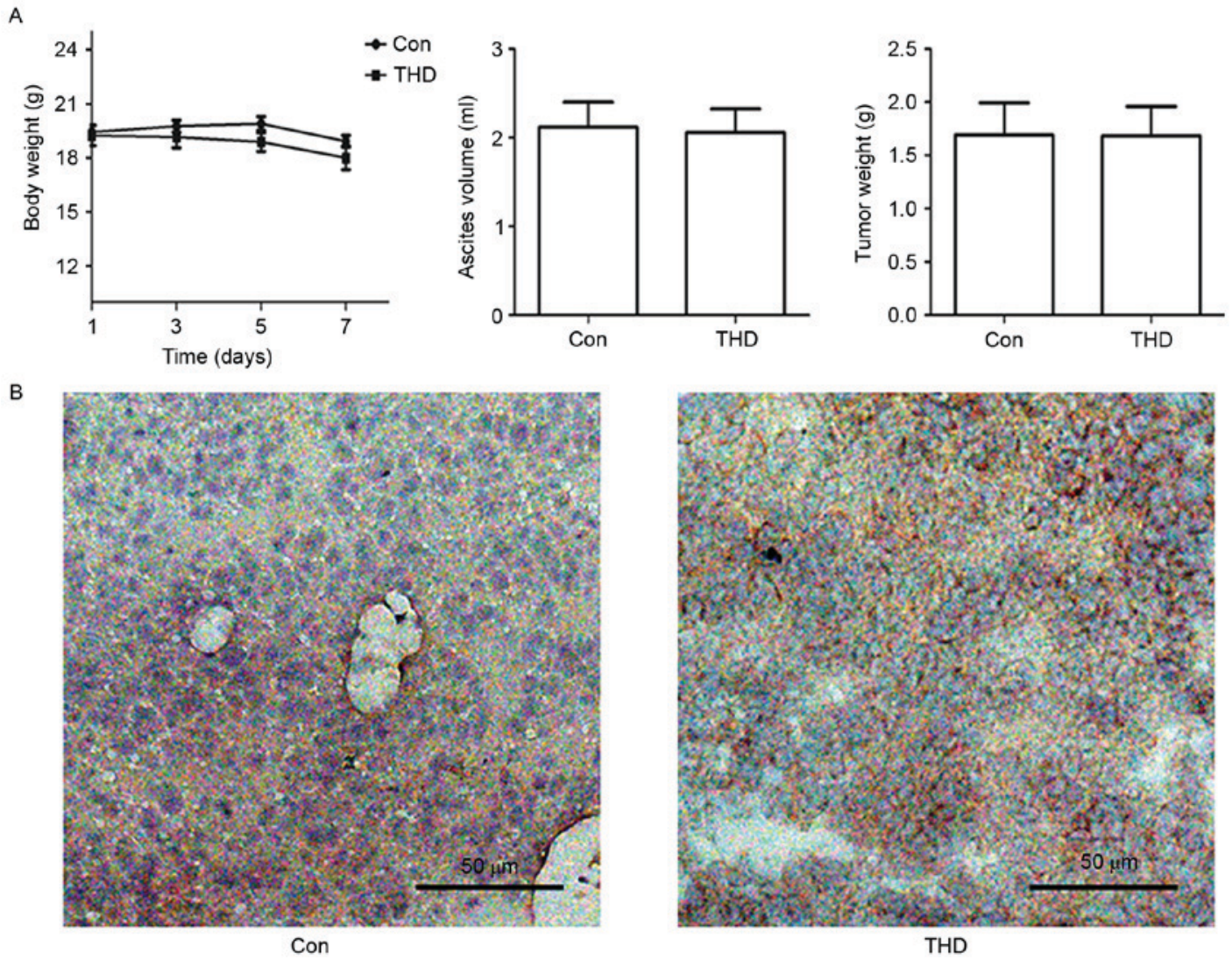

THD

Figure 5. Effect of THD on VEGFR1 protein expression levels in vivo. (A) CT26 cells were implanted into the abdominal cavity of BALB/c mice. Tumor-bearing mice received THD therapy or saline. Body weight, ascites volume and tumor weight were assessed. (B) Representative immunohistochemical images of VEGFR1 protein expression in the control group and THD-treated group. Brown staining indicates that tissues are positive for VEGFR1. Data are presented as the mean \pm standard deviation. THD, thalidomide; Con, control; VEGFR1, vascular endothelial growth factor receptor 1.

evaluated based on body weight, ascites volume and tumor weight over the course of 7 days. There was no significant difference in body weight, ascites volume or tumor weight between the THD group and control group ( $\mathrm{P}>0.05$; Fig. 5A). 


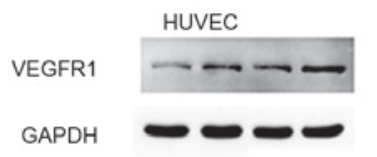

Con $\frac{0.5 \quad 0.8 \quad 1}{\text { Cisplatin }(\mu \mathrm{g} / \mathrm{ml})}$

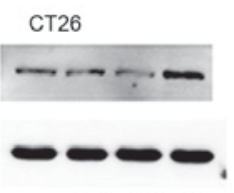

Con $\frac{0.5 \quad 0.8 \quad 1}{\text { Cisplatin }(\mu \mathrm{g} / \mathrm{ml})}$

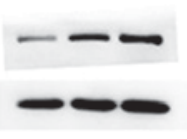

Con $\frac{5 \_10}{\text { Doxorubicin }(\mu \mathrm{M})}$

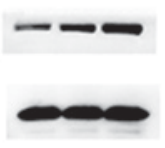

Con $\frac{5 \_10}{2}$

Doxorubicin $(\mu \mathrm{M})$

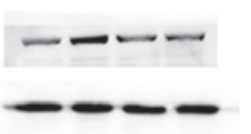

Con $\frac{10 \quad 20 \quad 40}{\text { Paclitaxel }(\mathrm{ng} / \mathrm{ml})}$

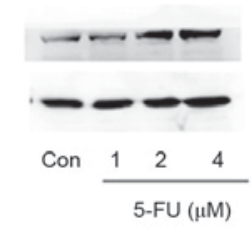

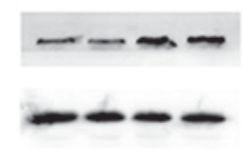

Con $\frac{10 \quad 20 \quad 40}{\text { Paclitaxel }(\mathrm{ng} / \mathrm{ml})}$

C

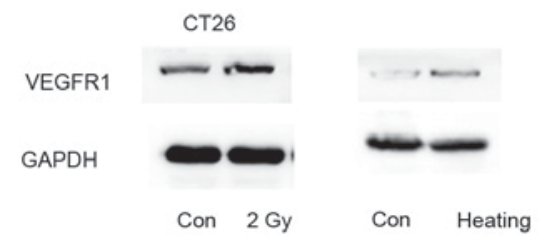

Figure 6. VEGFR1 acts as a stress-inducible molecule. (A) HUVECs and CT26 tumor cells were incubated with indicated concentrations of cisplatin, doxorubicin, paclitaxel and 5-FU, respectively. (B and C) HUVECs and CT26 tumor cells were irradiated with 2 Gy X-rays or heated at $47^{\circ} \mathrm{C}$ for 3 min. Protein expression levels of VEGFR1 in the CT26 and HUVECs cells were determined using western blot analysis. THD, thalidomide; Con, control; VEGFR1, vascular endothelial growth factor receptor; 5-FU, 5-fluorouracil; HUVECs, human umbilical vein endothelial cells.

Furthermore, the protein expression levels of VEGFR1 were increased in the THD-treated group compared with the control group according to immunohistochemical staining analysis (Fig. 5B). These data suggest that THD failed to inhibit CT26 murine tumor growth, but upregulated VEGFR1 protein expression levels in vivo.

VEGFRI is a stress-inducible molecule. In order to further determine whether VEGFR1 is a stress-inducible molecule, VEGFR1 expression levels were assessed in cells subjected to various stress-related situations. CT26 cells and HUVECs were exposed to chemotherapeutic drugs, including cisplatin, doxorubicin, paclitaxel and 5-FU, respectively. VEGFR1 expression levels were mostly upregulated following exposure to these chemotherapeutic agents compared with the respective control groups. However VEGFR1 in HUVECs for 20 and $40 \mathrm{ng} / \mathrm{ml}$ paclitaxel was lower than for $10 \mathrm{ng} / \mathrm{ml}$. It was hypothesized that an appropriate dosage may produce a stress response and increase the expression of VEGFR1, whereas too high a dosage would increase cell apoptosis. VEGFR1 expression did not increase in HUVECs treated with 20 or $40 \mathrm{ng} / \mathrm{ml}$ paclitaxel. (Fig. 6A). Furthermore, stress was induced in CT26 cells and HUVECs by irradiation with 2 Gy X-rays. VEGFR1 expression levels were markedly upregulated following irradiation compared with the control group (Fig. 6B and C). Additionally, cellular stress was induced in CT26 tumor cells and HUVECs by heating the cells at $47^{\circ} \mathrm{C}$ for $3 \mathrm{~min}$. VEGFR1 protein expression levels were increased in comparison with those in with the control group (Fig. 6B and C). Together, the data suggest VEGFR1 may be a stress-inducible molecule.

\section{Discussion}

In the present study, the growth-arresting and apoptosis-inducing effects of THD on tumor cells and endothelial cells were determined. Notably, VEGFR1 protein expression levels were upregulated in response to high concentrations of THD in vitro and in vivo. Furthermore, results suggested that the levels of ROS were increased in response to THD exposure, and the inhibition of ROS reduced VEGFR1 protein expression levels to an extent. Thus, we postulated that VEGFR1 may act as a stress-associated protein, and the results of further experiments indicated that VEGFR1 protein expression levels were elevated in response to various stress-associated situations, including chemotherapy, radiotherapy and thermotherapy.

VEGFR1 has been reported to be expressed on endothelial cells and in various types of cancer cells, including gastric cancer cells, colorectal carcinoma cells, breast cancer cells and lymphoma cells (19-23). However, the biological function of VEGFR1 remains to be fully elucidated. The present study assessed the effect of THD on HUVECs in vitro, and indicated that THD elevated the protein expression levels of VEGFR1. This upregulation of VEGFR1 protein expression was also observed on CT26 tumor cells. Similar phenomena were also observed in the SW480 and HCT116 human colorectal tumor cells. Furthermore, in the constructed in vivo murine model, THD failed to inhibit tumor growth and the protein expression levels of VEGFR1 were elevated by THD treatment. The extent of the apoptosis induced by THD treatment in CT26 cells and HUVECs suggests that the upregulation of VEGFR1 could be due to cellular stress caused by THD. The biosynthesis and accumulation of ROS, including superoxide anion radicals, 
hydrogen peroxide, hydroxyl radicals and oxygen, are central to oxidative stress-associated metabolism (38). The results of the present study suggested that exposure to THD increased intracellular ROS levels. Pretreatment of CT26 tumor cells with the antioxidant NAC prior to exposure to THD reversed the THD-induced elevation of VEGFR1 protein expression. Several stress-associated conditions for cells were explored in the present study, including chemotherapeutic agents, irradiation and heat shock. Exposure to these factors upregulated the protein expression levels of VEGFR1 in CT26 cells and HUVECs. These results indicate that the increased cell surface expression of VEGFR1 may be a cellular stress response.

Cellular stress responses, which are defense reactions, are an important part of physiology to either ensure cell survival or eliminate damaged or unwanted cells (39). Depending on the type of cellular stress and its severity, there are four primary types of response, including the heat shock response, the unfolded protein response, the DNA damage response and the response to oxidative stress (40). Stress-associated proteins have protective effects on cell survival (40). Well-known stress proteins are the heat shock protein (HSP) family. HSPs protect cells against damage in stressful conditions, which may facilitate tissue homeostasis and tissue regeneration (40). HSP70 enhances the survival of fibroblasts and promotes recovery from heat shock (41). HSP70 enhancement has a critical role in the recovery of striated muscle post-exercise (42). In a zebrafish model, treatment with HSP inhibitor I inhibited axonal elongation or visual function following injury (43). HSPs attenuate cellular apoptosis (44). HSP27 protects tumor cells from ultraviolet-induced apoptosis via the Akt and p21 signaling pathways (45). Increased HSP expression is associated with chemoresistance (46). High levels of HSP90AA1 have been demonstrated to increase chemoresistance to the chemotherapeutic agent cisplatin in SKOV3 cells (46). Furthermore, HSPs are upregulated in various tumors, including lung cancer (47), prostate cancer (48), breast cancer (49) and gastric cancer (50). They are typically associated with a poor prognosis (51); thus, they may provide a potential molecular target in cancer therapy (52). A previous study indicated that VEGF165 promotes the survival of leukemia cells via the HSP90-mediated induction of BCL-2 expression and apoptosis inhibition (53). However, further investigations are required to determine whether VEGFR1 serves a similar role, and protects cells from apoptosis.

In conclusion, the present study indicated a novel pharmacological property of THD and the results suggested that VEGR1 may be a stress-inducible molecule. The findings provide a basis for future investigations into the application of VEGFR1-targeted therapy to enhance the efficacy of current therapies.

\section{Acknowledgements}

The present study was supported by grants from the National Natural Science Foundation of China (grant nos. 81501609 and 81272523).

\section{References}

1. McBride WG: Thalidomide embryopathy. Teratology 16: 79-82, 1977.
2. Kim JH and Scialli AR: Thalidomide: The tragedy of birth defects and the effective treatment of disease. Toxicol Sci 122: 1-6, 2011.

3. Melchert $\mathrm{M}$ and List A: The thalidomide saga. Int J Biochem Cell Biol 39: 1489-1499, 2007.

4. Ito $\mathrm{T}$, Ando $\mathrm{H}$ and Handa $\mathrm{H}$ : Teratogenic effects of thalidomide: Molecular mechanisms. Cell Mol Life Sci 68: 1569-1579, 2011.

5. Singhal S, Mehta J, Desikan R, Ayers D, Roberson P, Eddlemon P, Munshi N, Anaissie E, Wilson C, Dhodapkar M, et al: Antitumor activity of thalidomide in refractory multiple myeloma. $\mathrm{N}$ Engl J Med 341: 1565-1571, 1999.

6. de Souza CM, Araújo e Silva AC, de Jesus Ferraciolli C, Moreira GV, Campos LC, dos Reis DC, Lopes MT, Ferreira MA, Andrade SP and Cassali GD: Combination therapy with carboplatin and thalidomide suppresses tumor growth and metastasis in 4T1 murine breast cancer model. Biomed Pharmacother 68: $51-57,2014$

7. Lee SM and Hackshaw A: A potential new enriching trial design for selecting non-small-cell lung cancer patients with no predictive biomarker for trials based on both histology and early tumor response: Further analysis of a thalidomide trial. Cancer Med 2: 360-366, 2013

8. Lv J,Liu N, Liu KW, Ding AP, Wang H and Qiu WS: A randomised controlled phase II trial of the combination of XELOX with thalidomide for the first-line treatment of metastatic colorectal cancer. Cancer Biol Med 9: 111-114, 2012.

9. Rezvani H, Haghighi S, Ghadyani M and Attarian H: Efficacy of taxotere, thalidomide, and prednisolone in patients with hormone-resistant metastatic prostate cancer. Urol J 9: 673-677, 2012.

10. Tunio MA, Hashmi A, Qayyum A, Naimatullah N and Masood R: Low-dose thalidomide in patients with metastatic renal cell carcinoma. J Pak Med Assoc 62: 876-879, 2012.

11. de Almeida MV, Teixeira FM, de Souza MV, Amarante GW, Alves CC, Cardoso SH, Mattos AM, Ferreira AP and Teixeira HC: Thalidomide analogs from diamines: Synthesis and evaluation as inhibitors of TNF-alpha production. Chem Pharm Bull (Tokyo) 55: 223-226, 2007.

12. Dmoszynska A, Podhorecka M, Manko J, Bojarska-Junak A, Rolinski J and Skomra D: The influence of thalidomide therapy on cytokine secretion, immunophenotype, BCL-2 expression and microvessel density in patients with resistant or relapsed multiple myeloma. Neoplasma 52: 175-181, 2005.

13. Marriott JB, Clarke IA, Czajka A, Dredge K, Childs K, Man HW, Schafer P, Govinda S, Muller GW, Stirling DI and Dalgleish AG: A novel subclass of thalidomide analogue with anti-solid tumor activity in which caspase-dependent apoptosis is associated with altered expression of bcl-2 family proteins. Cancer Res 63: 593-599, 2003.

14. Gutman M, Szold A, Ravid A, Lazauskas T, Merimsky O and Klausner JM: Failure of thalidomide to inhibit tumor growth and angiogenesis in vivo. Anticancer Res 16: 3673-3677, 1996.

15. Fantozzi A, Gruber DC, Pisarsky L, Heck C, Kunita A, Yilmaz M, Meyer-Schaller N, Cornille K, Hopfer U, Bentires-Alj M and Christofori G: VEGF-mediated angiogenesis Links EMT-induced cancer stemness to tumor Initiation. Cancer Res 74: 1566-1575, 2014.

16. Takahashi S: Vascular endothelial growth factor (VEGF), VEGF receptors and their inhibitors for antiangiogenic tumor therapy. Biol Pharm Bull 34: 1785-1788, 2011.

17. Fiorelli A, Vicidomini G, Di Domenico M, Napolitano F, Messina G, Morgillo F, Ciardiello F and Santini M: Vascular endothelial growth factor in pleural fluid for differential diagnosis of benign and malignant origin and its clinical applications. Interact Cardiovasc Thorac Surg 12: 420-424, 2011.

18. Shibuya M: Structure and dual function of vascular endothelial growth factor receptor-1 (Flt-1). Int J Biochem Cell Biol 33: 409-420, 2001.

19. Shibuya M: Vascular endothelial growth factor receptor-1 (VEGFR-1/Flt-1): A dual regulator for angiogenesis. Angiogenesis 9: 225-231, 2006.

20. Zhu H, Zhao C, Liu F, Wang L, Feng J, Zhou Z, Qu L, Shou C and Yang Z: Radiolabeling and evaluation of (64)Cu-DOTA-F56 peptide targeting vascular endothelial growth factor receptor 1 in the molecular imaging of gastric cancer. Am J Cancer Res 5: 3301-3310, 2015.

21. Lesslie DP, Summy JM, Parikh NU, Fan F, Trevino JG, Sawyer TK, Metcalf CA, Shakespeare WC, Hicklin DJ, Ellis LM and Gallick GE: Vascular endothelial growth factor receptor-1 mediates migration of human colorectal carcinoma cells by activation of Src family kinases. Br J Cancer 94: 1710-1717, 2006. 
22. Ning Q, Liu C, Hou L, Meng M, Zhang X, Luo M, Shao S, Zuo X and Zhao X: Vascular endothelial growth factor receptor-1 activation promotes migration and invasion of breast cancer cells through epithelial-mesenchymal transition. PLoS One 8: e65217, 2013.

23. Wang ES, Teruya-Feldstein J, Wu Y, Zhu Z, Hicklin DJ and Moore MA: Targeting autocrine and paracrine VEGF receptor pathways inhibits human lymphoma xenografts in vivo. Blood 104: 2893-2902, 2004

24. Kaplan RN, Riba RD, Zacharoulis S, Bramley AH, Vincent L, Costa C, MacDonald DD, Jin DK, Shido K, Kerns SA, et al: VEGFR1-positive haematopoietic bone marrow progenitors initiate the pre-metastatic niche. Nature 438: 820-827, 2005.

25. Qian BZ, Zhang H, Li J, He T, Yeo EJ, Soong DY, Carragher NO, Munro A, Chang A, Bresnick AR, et al: FLT1 signaling in metastasis-associated macrophages activates an inflammatory signature that promotes breast cancer metastasis. J Exp Med 212 1433-1448, 2015.

26. Kosaka Y, Mimori K, Fukagawa T, Ishikawa K, Etoh T, Katai H, Sano T, Watanabe M, Sasako M and Mori M: Identification of the high-risk group for metastasis of gastric cancer cases by vascular endothelial growth factor receptor-1 overexpression in peripheral blood. Br J Cancer 96: 1723-1728, 2007.

27. Zhou Z, Zhao C, Wang L, Cao X, Li J, Huang R, Lao Q, Yu H, Li Y, Du H, et al: A VEGFR1 antagonistic peptide inhibits tumor growth and metastasis through VEGFR1-PI3K-AKT signaling pathway inhibition. Am J Cancer Res 5: 3149-3161, 2015.

28. An P, Lei H, Zhang J, Song S, He L, Jin G, Liu X, Wu J, Meng L, Liu M and Shou C: Suppression of tumor growth and metastasis by a VEGFR-1 antagonizing peptide identified from a phage display library. Int J Cancer 111: 165-173, 2004.

29. Ye L, Yu G, Wang C, Du B, Sun D, Liu J, Qi T, Yu X, Wei W, Cheng J and Jiang Y: MicroRNA-128a, BMI1 polycomb ring finger oncogene and reactive oxygen species inhibit the growth of U-87 MG glioblastoma cells following exposure to X-ray radiation. Mol Med Rep 12: 6247-6254, 2015.

30. Chen H, Ye H, Meng DQ, Cai PC, Chen F, Zhu LP, Tang Q Long ZX, Zhou Q, Jin Y, et al: Reactive oxygen species and $\mathrm{X}$-Ray disrupted spontaneous $\left[\mathrm{Ca}^{2+}\right] \mathrm{I}$ oscillation in alveolar macrophages. Radiat Res 179: 485-492, 2013.

31. Gu ZT, Wang H, Li L, Liu YS, Deng XB, Huo SF, Yuan FF, Liu ZF, Tong HS and Su L: Heat stress induces apoptosis through transcription-independent $\mathrm{p} 53$-mediated mitochondrial pathways in human umbilical vein endothelial cell. Sci Rep 4: 4469, 2014.

32. Komorowski J, Jerczyńska H, Siejka A, Barańska P, Ławnicka H, Pawłowska $\mathrm{Z}$ and Stepień H: Effect of thalidomide affecting VEGF secretion, cell migration, adhesion and capillary tube formation of human endothelial EA.hy 926 cells. Life Sci 78 2558-2563, 2006.

33. Aydoğan S, Celiker U, Türkçüoğlu P, Ilhan N and Akpolat N: The effect of thalidomide on vascular endothelial growth factor and tumor necrosis factor-alpha levels in retinal ischemia/reperfusion injury. Graefes Arch Clin Exp Ophthalmol 246: 363-368, 2008.

34. Kozar K and Sicinski P: Cell cycle progression without cyclin D-CDK4 and cyclin D-CDK6 complexes. Cell Cycle 4: 388-391, 2005.

35. Baldin V, Lukas J, Marcote MJ, Pagano M and Draetta G: Cyclin D1 Is a nuclear-protein required for cell cycle progression in G1. Gene Dev 7: 812-821, 1993

36. Robson S, Pelengaris S and Khan M: c-Myc and downstream targets in the pathogenesis and treatment of cancer. Recent Pat Anticancer Drug Discov 1: 305-326, 2006.
37. Qiao Z, Yuan J, Shen J, Wang C, He Z, Hu Y, Zhang M and Xu C: Effect of thalidomide in combination with gemcitabine on human pancreatic carcinoma SW-1990 cell lines in vitro and in vivo. Oncol Lett 9: 2353-2360, 2015.

38. Gill SS and Tuteja N: Reactive oxygen species and antioxidant machinery in abiotic stress tolerance in crop plants. Plant Physiol Biochem 48: 909-930, 2010.

39. Chan CJ, Smyth MJ and Martinet L: Molecular mechanisms of natural killer cell activation in response to cellular stress. Cell Death Differ 21: 5-14, 2014

40. Fulda S, Gorman AM, Hori O and Samali A: Cellular stress responses: Cell survival and cell death. Int J Cell Biol 2010: 214074, 2010.

41. Liu RY, Li X, Li L and Li GC: Expression of human hsp70 in rat fibroblasts enhances cell survival and facilitates recovery from translational and transcriptional inhibition following heat shock. Cancer Res 52: 3667-3673, 1992.

42. Noble EG, Melling CW and Milne KJ: HSP, Exercise and Skeletal Muscle. Heat Shock Proteins Whole Body Physiol 5: 285-316, 2010.

43. Nagashima M, Fujikawa C, Mawatari K, Mori Y and Kato S: HSP70, the earliest-induced gene in the zebrafish retina during optic nerve regeneration: Its role in cell survival. Neurochem Int 58: 888-895, 2011.

44. Beere HM: 'The stress of dying': the role of heat shock proteins in the regulation of apoptosis. J Cell Sci 117: 2641-2651, 2004.

45. Kanagasabai R, Karthikeyan K, Vedam K, Qien W, Zhu Q and Ilangovan G: Hsp27 protects adenocarcinoma cells from UV-induced apoptosis by Akt and p21-dependent pathways of survival. Mol Cancer Res 8: 1399-1412, 2010.

46. Chu SH, Liu YW, Zhang L, Liu B, Li L, Shi JZ and Li L: Regulation of survival and chemoresistance by HSP90AA1 in ovarian cancer SKOV3 cells. Mol Biol Rep 40: 1-6, 2013.

47. Wen W, Liu W, Shao Y and Chen L: VER-155008, a small molecule inhibitor of HSP70 with potent anti-cancer activity on lung cancer cell lines. Exp Biol Med (Maywood) 239: 638-645, 2014.

48. Azad AA, Zoubeidi A, Gleave ME and Chi KN: Targeting heat shock proteins in metastatic castration-resistant prostate cancer. Nat Rev Urol 12: 26-36, 2015.

49. Calderwood SK: Heat shock proteins in breast cancer progression-a suitable case for treatment? Int J Hyperthermia 26: 681-685, 2010

50. Partida-Rodríguez O, Torres J, Flores-Luna L, Camorlinga M, Nieves-Ramírez M, Lazcano E and Perez-Rodríguez M: Polymorphisms in TNF and HSP-70 show a significant association with gastric cancer and duodenal ulcer. Int J Cancer 126 1861-1868, 2010.

51. Calderwood SK, Khaleque MA, Sawyer DB and Ciocca DR: Heat shock proteins in cancer: Chaperones of tumorigenesis. Trends Biochem Sci 31: 164-172, 2006.

52. Staufer K and Stoeltzing O: Implication of heat shock protein 90 (HSP90) in tumor angiogenesis: A molecular target for anti-angiogenic therapy? Current Cancer Drug Targets 10: 890-897, 2010

53. Dias S, Shmelkov SV, Lam G and Rafii S: VEGF(165) promotes survival of leukemic cells by Hsp90-mediated induction of Bcl-2 expression and apoptosis inhibition. Blood 99: 2532-2540, 2002. 